\title{
À espreita do Estado: reflexões sobre sua formação a partir das Independências na América
}

DOI

http://dx.doi.org/10.1590/2236-463320161303

\author{
Andréa Slemian \\ Universidade Federal de São Paulo, \\ São Paulo - SP, Brasil \\ slemian@terra.com.br
}

\begin{abstract}
Resumo
0 artigo tem por objetivo levantar alguns questionamentos sobre como pensar a história do Estado a partir das proposições apresentadas pelo texto de Juan Pro Ruiz no Fórum da Revista Almanack. Primeiramente, por meio da discussão da operacionalidade de o inserirmos como um constructo social dentro do marco de uma cultura estatal; em segundo lugar, tomando o problema do controle de seus significados enquanto categoria analítica, e mesmo em sua dimensão cultural. Toma-se como momento privilegiado para discussão o das Independências da América, e o Brasil como exemplo de propostas de análise.
\end{abstract}

\author{
Abstract \\ The article aims to raise some questions about how to think the history of \\ the State from the propositions presented by Juan Ruiz Pro in Almanack \\ Forum. Firstly, conceiving State as a social construct within the framework \\ of a State culture; secondly, considering the problem of the control of their \\ meanings while analytical category and in a cultural dimension. It takes as \\ privileged moment for discussion the Independence Era in America, and the \\ Brazil example of some analytics proposals. \\ Palavras-chave \\ Estado; Cultura; Instituições; Modernidade; Independência. \\ Keywords \\ State; Culture; Institutions; Modernity; Independence.
}

A revista publicou, há quatro anos, um outro sobre a temática, mais voltado para burocracia e construção estatal. Ver: GARAVAGLIA, Juan. Servir al Estado, servir al poder: la burocracia en el proceso de construcción estatal en América Latina. Almanack, Guarulhos, n.3, p. 5-26, maio 2012. Disponivel em http://www.almanack.unifesp.br/ index.php/almanack/article/view/907. Acesso em: 01 maio 2016.

Enhorabuena chega uma nova reflexão acerca da construção do Es-

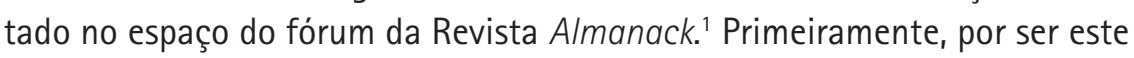
um veículo que tem se dedicado, há alguns anos, ao estudo de variadas faces deste fenômeno em todo mundo entre os séculos XVIII e XIX, e que se propõe a discuti-lo assumidamente diante do momento atual de crise do modelo de Estado-nação evidente, ao menos, desde o atual contexto da globalização. Crise esta que merece também ser pensada a partir da percepção de que jamais se cobrou tanto dele no atendimento às mais variadas demandas sociais e políticas, individuais e/ou coletivas. Em segundo lugar, pela força com que neste contexto sua evocação segue representando, sendo, para além de um topos, uma categoria fundamental para as ciências humanas, mesmo diante da sua negação promovida por muitos setores e agentes sociais há algumas décadas, supostamente enquanto fórmula ultrapassada para entendimento das sociedades. É fato que falar em Estado hoje signifi- 
Aqui seguimos LEMPERIĖRE, Annick. La historiografía del Estado en Hispanoamérica. Algunas Reflexiones. In: PALACIOS, Guillermo (coord.). Ensayos sobre la nueva Historia Política de América Latina, siglo XIX. México: El Colegio del Mexico, 2007, p. 45-62, no seu diagnóstico que, cremos, persiste após quase dez anos.

3

Neste sentido, e para o espaço ibérico, é fundamental se ter em mente o impacto de obras como as de António Manuel Hespanha e de Bartolomé Clavero.

RAG0, Margareth. 0 efeito-Foucault na historiografia brasileira. Tempo Social, São Paulo: USP, 7 (12), p. 67-82, 1995.

5

Para uma sintese que produz um elucidativo apanhado das obras que ai caberiam, ver PIMENTA, João Paulo. The Independence of Brazil: a review of the recent historiographic production. E-journal of Portuguese History, v.7, n.1, 2009, p.64-85.

CARVALHO, José Murilo de. A construção da ordem. A elite política imperial. Brasilia: UnB, 1981; MATTOS, Ilmar Rohloff de. O tempo saquarema. A formação do Estado imperial. Rio de Janeiro, Access Editora, 1999. ca estar no marco de enunciação de um discurso circunscrito ao momento genericamente descrito como de modernidade, do qual, não antes do final dos Setecentos, somos inegáveis herdeiros. Daí ser difícil não contaminar-se pelo que ele representa coletivamente como um dever ser onipresente $e_{\text {, }}$ por vezes, monolítico em nossa vida cotidiana, de cujo excesso ou falta se reclama ou se quer livrar, a depender do contexto. 0 que significa ao mesmo tempo - num exercício de ficção primária-, que se o termo fosse retirado do dia para noite de todos os dicionários existentes, a compreensão de nosso tempo presente seria plenamente impossibilitada.

Uma outra razão não nos parece menos importante sobre a fecundidade de lançarmos luz à questão do Estado neste momento: a carência de trabalhos que discutam, à luz de uma renovação dos estudos sobre história institucional e administrativa, o fenômeno estatal, especialmente no que toca à América ibérica. ${ }^{2}$ Neste sentido, há que se comprovar que os historiadores, em comparação com os cientistas sociais ou mesmo cientistas políticos, contribuíram menos em termos teóricos para o avanço dos temas estatais, ainda que fossem os primeiros responsáveis em descortinar os problemas para o uso do termo para sociedades que não aquelas surgidas nos últimos dois séculos, e no espaço ocidental. Um destaque merece ser dado aos historiadores do direito neste caminho. ${ }^{3}$ Mas se é verdadeiro que a revalorização do Estado é visivel hoje, falar no seu nome ainda significa encontrar certa resistência e um ar de indisposição, face à identificação que se pode fazer do mesmo com as historiografias institucionais que, sobretudo na América Latina, tenderam a possuir um caráter oficial não poucas vezes associada aos regimes ditatoriais vividos com força durante grande parte do século XX. Não à toa, a ênfase com que se renovou a historiografia no nosso contexto latino-americano foi movida em grande parte pela chamada história social e a agenda das micro-histórias de grupos subalternos e indivíduos, as quais cumprira um papel político decisivo na afirmação dos mesmos como sujeitos sociais até então alijados, de maneira contundente, dos espaços de representação que historicamente se constituíram nos processos de construção destes Estados em meio a sociedades tão desiguais. É verdade que tal ênfase vem recebendo uma forte inflexão a partir da implosão dos paradigmas sociais colocados em cena sobretudo a partir dos anos 70, mas ela segue sendo, ao menos no Brasil, uma rama potente de parte de nossa produção historiográfica. ${ }^{4}$

Em se tratando mais especificamente do tema da Independência e arranque do processo de formação de um Estado nacional brasileiro, ele ganharia impulso com a chamada renovação dos estudos de história política que veio à tona com força a partir dos anos 1990, especialmente de abordagens que se valeriam de culturas, vocabulários e sociabilidades políticas. ${ }^{5} \mathrm{Da}$ mesma forma, na agenda de uma "história cultural do político", tal qual tratada por Juan Pro Ruiz no texto que dá o tom para a discussão deste fórum, e que se revela bastante pertinente para ser discutido no contexto brasileiro. Embora trate da Espanha, Pro nos faz refletir sobre formas teórico-metodológicas que envolve pensar este processo reintroduzindo o Estado como uma de suas variáveis fundamentais. Ainda que para muitos, como demonstra no artigo e em sua própria obra geral, o Estado nunca deixou de ter uma posição privilegiada. 0 que se nota igualmente com força na historiografia brasileira sobre o período, tendo em vista que os estudos já clássicos sobre o tema, como os de Jose Murilo de Carvalho e de IImar Mattos, na década de 1980, e com perspectivas distintas, o tinham como caro. ${ }^{6}$ 
BENIGNO, Francesco. Ancora lo 'stato moderno' in alcune recenti sintesi storiografiche. Storica, Roma: Viella, n. 23, p. 119, 2002.
É verdade que, no seu livro saído posteriormente, BENIGNO, Francesco. Las palabras del tiempo. Un ideario para pensar históricamente. Madrid: Cátedra, 2013, p. 37-41, o autor afirmaria a atual eminência de um novo regime de historicidade que se traduziria também pela percepção de que, terminada a experiência da chamada modernidade, novos objetos e, sobretudo, enfoques passaram a ser evidentes.
Nossa intenção nestas páginas é propor, a partir do texto de Pro Ruiz, algumas reflexões em torno do Estado como categoria central à análise histórica, em especial no que toca ao processo de construção do brasileiro após a Independência, inserindo-o no conjunto de seus congêneres americanos. Estas reflexões serão aqui divididas em dois conjuntos de questionamentos: primeiramente, o da operacionalidade do seu termo dentro ou fora do marco de uma cultura estatal; em segundo lugar, do problema de seus significados enquanto categoria analítica, e mesmo da relevância da dimensão cultural para explicação de seu processo. Sem maiores pretensões que não seja seguir este debate, estamos convencidos que ele representa um ponto vital para nossa inserção como historiadores no debate atual acerca dos questionamentos quanto aos pressupostos, caráter e legitimidade dos Estados.

\section{Estado e o marco de uma cultura estatal}

Há pouco mais de uma década, Francesco Benigno, em um artigo aparentemente de simples questionamento sobre o que denominava ser "ainda" o tema do Estado, tocava em um ponto que cremos sensivel no que se refere à relação entre categorias e suas histórias/memórias particulares. Ao comentar algumas obras então recém lançadas, e que recolocavam a temática do Estado, mesmo que por caminhos diversos, reagia elegantemente à ideia de que o mesmo seria um "cadáver" sepultado pelos historiadores, e alçava os livros comentados à condição de "testemunho interessante e indubitavelmente estimulante da sensibilidade historiográfica de nosso tempo"? Sua reflexão partia da percepção, que reconhecia sabida, de que nenhuma construção intelectual pode separar-se completamente de um ser social coletivo que dá sentido à produção e reprodução das suas palavras. Deste modo, por mais contraditórias que identificasse serem as então presentes análises acerca do Estado, poder-se-ia argumentar que todas estavam inseridas no marco, se podemos dizer assim, de uma cultura estatalista que ainda projeta, consciente ou inconscientemente, alguns dos sentidos contidos e controlados na acepção da palavra desde, ao menos, o esforço de criação dos modernos Estados nacionais. Mas esta cultura estaria passando por um momento de inflexão e, por isso, a reflexão de Benigno não parava por aí. Ao tocar no problema da utilização da categoria para antes da modernidade, deixa claro como ela possui irrefutavelmente um componente temporal, seja na determinação de seus primórdios, seja na de sua finitude, ambas determinantemente vinculadas ao momento presente do observador. Desse modo, é significativo que, mesmo após a forte crítica feita pela historiografia (o que inclui a do direito) à possibilidade de utilização da categoria de Estado moderno para o que se foi convencionando, sobretudo a partir da década de 80, como peculiar ao Antigo Regime, alguns a sigam defendendo; da mesma forma, que a crise de paradigmas que envolve a própria legitimidade do Estado há algumas décadas, e talvez sua quase completa extinção como conceito operacional no mundo de hoje, determine o universo analítico ao nosso atual alcance. ${ }^{8}$

Se tomamos como válida, por um lado, esta imponderável identificação discursiva entre a bagagem conceitual daquele que interpreta o passado e a de seus atores históricos e, por outro, a alteração cotidiana que passamos atualmente no marco dos valores estatais vividos quase como um sem futuro, o campo para experimentação de abordagens acerca do Estado parece ser ainda mais frutifero. E nisso estamos com Benigno, e entre as obras de sensibilidade está igualmente o esforço de Juan Pro Ruiz na discussão sobre o 
9

Sobre isso, ver as ponderações feitas por GARRIGA, Carlos; SLEMIAN, Andréa. "Em trajes brasileiros": justiça e constituição na América ibérica (c. 1750-1850). Revista de História (USP), v.169, p.181-221, 2013.

10

Ver, ao menos, GRIMM, Dieter. Constitucionalismo y derechos fundamentales. Madrid: Trotta, 2006.

11

A bibliografia acerca da questão é amplíssima. Ver, para efeitos de sintese, BOBBI0, Norberto; BOVERO, Michelangelo. Sociedad y Estado en la Filosofía Política Moderna. Mexico: Fondo de Cultura Economica, 1979; CLAVERO, Bartolomé. Happy Constitution. Cultura y lengua constitucionales. Madrid: Trotta, 1997, cap. 1.

12

A bibliografia acerca da questão é amplissima. Ver, para efeitos de sintese, BOBBI0, Norberto; BOVERO, Michelangelo. Sociedad y Estado en la Filosofía Política Moderna. Mexico: Fondo de Cultura Economica, 1979; CLAVERO, Bartolomé. Happy Constitution. Cultura y lengua constitucionales. Madrid: Trotta, 1997, cap. 1.

13

Para o tema, KOSELLECK, Reinhart. Futuro Passado. Contribuição à semântica dos tempos históricos. Rio de Janeiro: Contraponto/Editora PUC-RJ, 2006, segue sendo uma das principais referências.

14

0 que teria seu exemplo mais bem acabado na obra de Hegel. Para uma sintese da questão, ver GARRIGA, Carlos. Legislación y códigos. In: LORENTE, Marta; VALLEJO, Jesús. Manual de Historia del Derecho. Valencia: Tirant lo Blanch, 2012, p.407-449. caso da Espanha. Neste sentido, este último é claro em marcar o ineditismo do processo histórico que analisa, tanto do ponto de vista das instituições e ações que foram sendo gestadas para reformas das estruturas herdadas, como do das disputas políticas que ganham conformação e espaço entre os projetos de governo e sociedade no século XIX. Assim o Estado espanhol não teria sido uma simples continuidade com o aperfeiçoamento de um processo iniciado anteriormente - por exemplo, com as reformas ilustradas -, mas algo essencialmente novo que tomou corpo a partir da crise da monarquia no início dos Oitocentos. A novidade do Estado transparece em um amplo leque de transformações, enquadramento que parece demonstrar o quanto a implosão e crise dos atuais Estado está presente na análise de Juan Pro sob a forma de renovação dos estudos historiográficos das últimas duas décadas, pelo menos.

No entanto, sem adentrar em uma polêmica que nos parece verdadeiramente infrutífera acerca de mudanças e continuidades que caberiam a este processo ${ }^{9}$, estamos de acordo acerca da novidade desse Estado se temos em mente, sobretudo, a construção de uma cultura estatal, mais precisamente, da alteração das condições de enunciação dos discursos dentro de um novo contexto dos Oitocentos. 0 que significou a projeção de um ideário de realização futura para os regimes representativos baseada em uma série de parâmetros que deveriam contemplar toda uma agenda jurídico-política do que seriam posteriormente os Estados de direito. ${ }^{10}$ Dessa forma, pode haver sentido marcarmos como um dos momentos de inflexão para a construção dessa cultura as teses jusnaturalistas que, desde ao menos o século XVII, tensionaram a concepção de ordem natural tradicional ao proporem uma outra, voluntarista, que concebia a separação entre duas esferas distintas: a do estado de natureza e a do estado civil. ${ }^{11}$ Imaginar que o viver em sociedade seria uma escolha, que condicionaria de forma positiva ou negativa as liberdades e direitos, abria espaço para se conceber o governo como uma construção artificial, bem como ao homem como abstrato e universal - por mais que saibamos de sobra o potencial excludente aí contido, reservando aos homens brancos, pais de famílias, proprietários e católicos um papel de destaque.

Mas é bem verdade que a gestação da concepção da sociedade como uma interposição entre indivíduo e Estado criou uma outra matriz de pensamento, que teve consequências decisivas para compreensão deste último, cabendo ser entendida num momento em que seus protagonistas, fossem ideólogos ou agentes práticos, foram violentamente arrastados ao torvelinho que significou uma alteração de caráter temporal a partir de finais do século XVIII. ${ }^{12} \mathrm{Em}$ contraposição às teses contratualistas, a projeção de uma esfera social autoregulada para onde confluiriam todos os indivíduos sob a postulação de uma ideia de mercado, teria sido decisiva na conformação da alma mater daquele que passaria, desde então, a ser legitimamente responsável por sua manutenção. ${ }^{13}$ Mesmo que sem a absoluta centralidade que o próprio Estado viria a adquirir posteriormente, sua concepção teria desde então um papel estratégico no ordenamento social. Tal teorização tomaria corpo nas primeiras décadas do Oitocentos, fornecendo à política o papel demiúrgico de composição da sociedade - compreendida como naturalmente dispersa -, e desaguaria na ficção de uma entidade autônoma e reguladora, guardiã dos direitos dos indivíduos que deveriam manter uma relação de exterioridade no que se tratasse do universo das liberdades civis. ${ }^{14}$ Várias e várias conformações e projetos, inclusive antagônicos entre si, poderiam 
15

Um ótimo exemplo de como a leitura do passado não apenas serviu de arma política, mas em moldar as formas de se pensar a história do Brasil no momento da independência, está em SANTOS, Cristiane Alves C. dos Santos. Escrevendo a história do futuro: a leitura do passado no processo de independência do Brasil. Dissertação (Mestrado em História Social). Faculdade de Filosofia, Letras e Ciências Humanas, Universidade de São Paulo, São Paulo, 2010.

\section{6}

Sobre o tema ver, COSTA, Pietro ; ZOLO, Danilo (orgs.). O Estado de Direito. História, teoria, crítica. São Paulo: Martins Fontes, 2006, especialmente 0 capítulo assinado por Costa.

17

A bibliografia aqui é mais do que ampla. Algumas coletâneas podem servir de boa amostra da pujança do tema: JANCSÓ, István (org.). Brasil. Formação do Estado e da nação. São Paulo/ljui: Hucitec/Fapesp/ Unijui, 2003; CALDERÓN, Maria Teresa; THIBAUD, Clément (orgs.). Las revoluciones en el mundo atlántico. Bogotá: Taurus/Universidad Externado de Colombia, 2006; FRASQUET, Ivana; SLEMIAN, Andréa. (orgs.). De las independencias iberoamericanas a los estados nacionales (1810-1850): 200 años de historia. Madrid/Frankfurt: Iberoamericana/ Vervuert, 2009; CHUST, Manuel; SERRANO, José (eds.). Debates sobre las independencias iberoamericanas. Frankfurt am Main: VervuertIberoamericana-Ahila, 2007; e ANNINO, Antonio (coord.). La revolución novohispana, 1808-1821. México: CIDE/FCE/Conaculta/INEHRM/Fundación Cultural de la Ciudad de México, 2010. Cabe um destaque à análise de PIMENTA, João Paulo. Brasil y las independencias de Hispanoamérica. Castelló de la Plana: Universitat Jaume I, 2007, na aproximação entre a Américas espanhola e portuguesa. ser mapeados, mas mesmo as críticas mais radicais a essa matriz partiriam de um mesmo ethos.

Este é o ponto que nos interessa mais particularmente: a possibilidade de que tal ethos foi fruto de uma operação por si mesma conjunta, datada desde os coevos, entre uma ação mais direta na sua construção e a projeção discursiva de um futuro que, irremediavelmente, colocava novas molduras no olhar sobre a história. Nesse sentido, a alteração temporal promovida pela modernidade, na virada do século XVIII para o XIX, trouxe consigo a percepção de uma ruptura temporal que daria forma a uma cultura sobre 0 Estado que tanto o legitimaria, como projetaria os elementos que deveriam ser intrínsecos ao mesmo em leituras sobre o passado. ${ }^{15}$ Longe estamos de negar que esse processo fora marcado por uma miriade de conflitos, do qual a emergência de vários projetos políticos de governo foi uma de suas manifestações, como bem demonstra Juan Pro para o caso espanhol. Mas fossem radicalmente distintos os projetos, fosse imenso o debate que se inaugurava sobre sua história, teriam eles que passar pelos elementos que se associavam ao dever ser de um Estado, racionalizado, constitucional, com divisão de poderes, respeito a um padrão de direitos individuais, entre várias outros. ${ }^{16}$

É uma inverdade que a América ibérica não estaria igualmente no epicentro desse processo. Desde as independências, o grande desafio que se colocava no horizonte era o da formação de unidades políticas estáveis diante da diversidade dos territórios que faziam até então parte das monarquias portuguesas e espanholas. ${ }^{17}$ Se em um primeiro momento - perceptível já em Cádiz, obviamente - os projetos em disputa lidaram com uma engenharia constitucional baseada em equilíbrio de poderes e contra poderes que visavam construir governos representativos com garantia de direitos (com a afirmação da religião católica, diga-se de passagem), logo se imporia uma agenda guiada pela arquitetura de um Estado como regulador social e moderador das disputas. As quais efetivamente Ihe foram permanentes, há que se dizer. Uma das formas de notarmos a profunda efetividade de um marco estatal nesse espaço, e mesmo sua prevalência até hoje, é a observação do seu contrário, sob a forma do que poderíamos chamar de discurso das "ausências". Construído sempre sobre uma alteridade - em geral, as experiências europeias ou a norte-americana, mas também a da América espanhola quando se tratava de sua evocação como contrária ao Império do Brasil -, suas falas evocavam a "falta de preparação", de "luzes" ou mesmo de "civilização" para se colocarem em marcha as instituições necessárias, ou esperadas.

0 que nos chama a atenção é o fato de que se trata de um topos disseminado na boca de muitos dos próprios protagonistas desse processo, ainda que as soluções propostas pudessem ser muito distintas, das mais conservadoras às mais radicais. Uma delas, destinada a barrar grandes inovações, esteve ancorada na retórica em defesa de não ser "prudente" se alterar, de forma sumária, todas as normas vigentes. Seu substrato era o da manutenção da cultura jurídica existente, transvertido num discurso de serem as nações do Novo Mundo muito jovens, incapazes de lidar com inovações em todos os seus campos. 0 que se iria observar no caso do Brasil, mas em toda América ibérica de alguma forma, em que muitos dos projetos políticos foram capitaneados por crioulos que, em meio às sociedades pluriétnicas aí existentes e à ascensão possibilitada às camadas subalternas, encontravam no passado colonial e na sua tradição espanhola/portuguesa um ponto de união contra possiveis alterações radicais do status quo. Mas o mesmo discurso da "falta" 
18

LEMPÉRIĖRE, Annick. El Estado en los espacios ibéricos: ¿orden natural o máquina perfomativa? In: FERNANDEZ SEBASTIÁN, Javier (dir.); LEMPERIĖRE, Annick. (ed.). Diccionario politico e social del mundo americano. Estado. Madrid: UPV/ Centro de Estudios Políticos e Constitucionales, 2014, p. 15-33.

19

ROSANVALLON, Pierre. L'Etat en France de $1789 \dot{a}$ nous jours. Paris: Éditions du Seuil, 1990. caberia na voz daqueles que, almejando por transformações mais radicais, espelhavam-se naquelas externas que fornecessem legitimidade para propostas mais arrojadas. 0 que havia em comum em umas e outras era a referência a um dever ser que, mesmo irrealizável no momento, projetava-se no marco de padrões que, de forma conflitiva, foram se estabelecendo.

\section{E como pensamos o Estado?}

Annick Lemperière, ao analisar os significados do termo Estado desde finais do século XVIII no mundo ibero-americano, discute como desde então sua evocação enquanto uma categoria política esteve vinculada a uma dupla acepção. Por um lado, a de algo abstrato e simbólico vinculado, metaforicamente, seja à imagem do soberano e à unidade do "corpo político", seja como titular, ele mesmo, da máxima autoridade e jurisdição; por outro, a de algo muito concreto, como uma realidade do mundo terrestre, sobre a qual não haveria o que discutir. ${ }^{18}$ Já era visível como, desde então ao menos, observa-se sua utilização vinculada a um nível da realidade com aspiração a um padrão de administração, para além do campo das disputas, e também projeção de suas instituições. Distintas acepções que seguiriam operativas, e jogariam um papel importante no que tocasse à função pública para compreensão dos projetos de Estado que se desenhariam ao longo do século XIX.

0 que nos permite afirmar que, historicamente, a ação dos agentes sociais no que tocava ao fenômeno Estado não devia ser redutível à esfera do jogo político, mas também observada mediante uma complexa arquitetura de dispositivos herdados, construidos e reconstruidos permanentemente. É fato que uma linhagem historiográfica muito conservadora e potente contaminou o objeto Estado, desde seu nascedouro, de um caráter não poucas vezes laudatório acerca do mesmo. 0 que faz com que até hoje a história das instituições tenha, de entrada, um ranço oficioso e marcado por preconceitos do olhar de muitos historiadores. Mas a crítica demolidora aos paradigmas vigentes vivida a partir dos anos 1960 nas ciências sociais provocaria uma série de reações e novos posicionamentos na busca pela compreensão de novas formas para se pensar Estado e instituições estatais. Em especial no que toca a arquitetura dos poderes e da política articulada a uma dimensão cultural dos mesmos.

Do ponto de vista historiográfico, é impensável referir-se ao Estado sem que se estude, ao menos, alguma dimensão do que conceberíamos como administração, mesmo sem o reduzirmos a ela. Ainda que a história das revoluções de finais do século XVIII e inícios do XIX, como foram as independências da América politicamente falando, tenham colocado no horizonte dos agentes sociais inéditas possibilidades de alteração de agenda social, estudar o Estado significa perguntar-se acerca de como uma engenharia social de relações pode ser construída. Nesse sentido, nos parecem especialmente instigantes, e mesmo divisoras de águas nos estudos vinculados à renovação da história política, as proposições de Pierre Rosanvallon sobre o Estado. ${ }^{19}$ Partindo da concepção que este último deve ser entendido na matriz da sua relação com a sociedade civil, aponta modalidades específicas para sua compreensão - desde a construção da ideia de uma autonomização do político, passando pelo discurso do Estado como responsável por instituir o social, proteger os indivíduos e regular a economia -, sem perder de vista a relevância de sua dimensão institucional e administrativa. Todas movidas por um discurso que se constrói no marco da projeção estatal a partir do século XIX. 
20

Ver, ao menos: STEINMETZ, George (org.). State/ Culture. State-formation after the Cultural Turn. Ithaca: Cornell University Press, 1999.

21

Valeria à pena aqui acompanhar o debate no campo que tem visibilidade em ADAMS, Julia (ed.) (et. alli). Remaking Modernity: Politics, History, and Sociology (Politics, History, and Culture). Durham: Duke University Press Books, 2005; e SEWELL Jr., William H.. Logics of History: Social Theory and Social Transformation. Chicago: University of Chicago Press, 2005.

22

Esta linha potente gerou alguns importantes trabalhos do ponto de vista da construção estatal que mais recentemente podem ser vistos em GARAVAGLIA, Juan Carlos; PRO RUIZ, Juan (orgs.). Latin American Bureaucracy and the State Building Process (1780-1860). Newcastle: Cambridge Scholars Publishing, 2013, p. 402-427.

23

BOURDIEU, Pierre. Sobre o Estado. Cursos no Collège de France (1989-92). São Paulo: Companhia das Letras, 2014. p. 30.
No entanto, acreditamos que a renovação das últimas décadas, na historiografia do Estado, seja ainda mais devedora das abordagens que valorizaram sua dimensão cultural do que aquela vinculada ao campo de estudos da política (ainda que esta esteja, de alguma forma, sempre presente). ${ }^{20} 0$ que sem dúvida está relacionado com a crítica cortante e radical à concepção dos sujeitos históricos como agentes plenamente conscientes e sempre portadores de uma agenda de ação política, muito marcada pelas teses foucaultianas e também pela antropologia culturalista desde os anos 1960. Renovação que foi muito bem consolidada nas proposições de Pierre Bourdieu e em outras dela derivadas. Mas não há como negar que este movimento teria múltiplas dimensões e incidiria de forma igualmente diferente em outros campos historiográficos já estabelecidos. Juan Pro parte dessa perspectiva crítica, que referenda como "giro culturalista", e sobre a qual gostaríamos de agregar alguns questionamentos.

Em primeiro lugar, embora sejam plausíveis muitas das criticas feitas à sociologia histórica, especialmente no que toca à explicação que tende a "considerar a construção dos Estados como um processo de acumulação de recursos em mãos de um poder centralizado", conforme as palavras do próprio Pro Ruiz, algumas de suas matrizes nos aparecem especialmente inspiradoras. ${ }^{21} \mathrm{Em}$ particular aquela de matriz weberiana, e que nos permite olhar as formações dos Estados-nações como complexos problemas historiográficos, ainda parece conservar uma fecunda possibilidade enquanto geradora de perguntas relevantes aos historiadores no tocante à construção de instituições e das formas de se servir ao Estado. 0 que só pode efetivamente se realizar se as oposições heurísticas - tradicional/moderno; público/ privado; patrimonial/racional - e os processos que se percebem por trás das definições de monopólio da coerção e desapropriação dos meios privados de administração, forem matizadas, pensadas em sua historicidade e em configurações diversas e mesmo contraditórias. Relações de tipo pessoal e clientelar não se apresentam como "dissolvidas" ou ultrapassadas por outras, de corte "burocrático" e "impessoal", mas são reinventadas, marcadas por novos impasses diante da imperiosa eficácia do discurso legitimador das primeiras, mais do que isso, frente à necessidade de apresentar novos argumentos afeitos aos critérios meritocráticos próprios em tempos de marco estatal. ${ }^{22}$ Se tomarmos em conta especialmente a questão do monopólio da violência, tão precisamente recolocados por Bourdieu em termos de "monopólio da violência simbólica legítima", entramos em cheio no cerne da questão: o Estado só tem existência por um princípio de produção e representação legítima do mundo social. ${ }^{23}$ Sua existência, portanto, está longe de poder ser medida apenas por sua dimensão institucional (ou mesmo legalista), ainda que esta seja elemento importante na sua reprodução.

Tomemos um exemplo do Império do Brasil e que toca especialmente à construção das províncias. Poder-se-ia argumentar que, com a Independência, se articula rapidamente - e é mesmo rapidamente, se compararmos com a América espanhola - um discurso potente em nome da necessidade da unidade política, e que coloca em ação uma série de reformas que visavam garantir a "modernização" de suas instituições. É verdade que a força desse discurso fez-se também por reações a ele, cujos elementos, por mais que radicalmente distintos do ponto de vista da arquitetura dos poderes, partilhariam de um mesmo marco estatal. Uma das medidas precocemente tomadas dizia respeito à circunscrição do espaço das províncias, ao mesmo tempo que, pouco anos depois, viria uma reformulação das antigas Câmaras 
Uma importante circunscrição das províncias se daria no âmbito das Cortes de Lisboa, com a proposta de criação das Juntas de Governo em 1821. Logo após a Independência, uma lei de 1823 instituia um presidente de província para cada qual, com uma marcação de suas atribuições. Poder-se-ia argumentar que o desenho mais definido do seu espaço se daria com o Ato Adicional de 1834 que instituiria, definitivamente, as Assembleias legislativas provinciais. Ver: BERBEL, Márcia; FERREIRA, Paula. Soberanias em questão: apropriações portuguesas sobre um debate iniciado em Cádis. In: BERBEL, M.; OLIVEIRA, Cecília Helena de S. (org.). A experiência constitucional de Cádis Espanha, Portugal e Brasil. São Paulo: Alameda, 2012, v. 1, p. 169-200; SLEMIAN, Andréa. Sob o império das leis: constituição e unidade nacional na formação do Brasil (1822-1834). São Paulo: Hucitec, 2009.

25

Importantes referências são os trabalhos de GOUVÊA, Maria de Fátima Silva. 0 império das províncias: Rio de Janeiro, 1822-1889. Rio de Janeiro: Civilização Brasileira, 2008; e DOLHNIKOFF, Miriam. O Pacto Imperial: Origens do federalismo do Brasil. São Paulo: Globo, 2005.

26

COSER, Ivo. Visconde do Uruguai, centralização e federalismo no Brasil, 1822-1866, Belo Horizonte: Editora UFMG, 2008; SLEMIAN, Andréa. As 'leais corporações'. Revista do Arquivo Público Mineiro, v. L, p. 24-33, 2014.

27

Já foi por demais criticada a concepção, bastante recorrente no Brasil até a década de 90, que as ideias "liberais" estariam fora do lugar durante todo o século XIX, produzindo uma modernização apenas de fachada. Longe de nós afirmar algo antagonicamente ao contrário, o que padeceria de outro equívoco. 0 que nos parece ser fundamental é entender exatamente a combinação de elementos e dispositivos institucionais temporalmente distintos em uma ordem que se pretendia nova. Sobre a questão, consideramos sugestivas as proposições de COSTA, Wilma P.; SLEMIAN, Andréa, The Justice System, the National Guard and Control of Public Order: the Brazilian Empire in the Initial Decades of the Nineteenth Century. In: GARAVAGLIA, Juan Carlos; PRO RUIZ, Juan (orgs.). Op. cit.

28

Ver STEINMETZ, George. Introduction: culture and the State. In: STEINMETZ, Op. Cit, p. I-49.

29

BENIGNO, Francesco. Estado. In: BENIGNO,

Las palabras del tiempo; GARRIGA, Carlos. La cuestión es saber quién manda ? Historia política, história del derecho y 'punto de vista'. PolHis, n.10, p.89-100, 20. semestre 2012. municipais. ${ }^{24}$ Esta última, mimetizada pela lei de 20 de outubro de 1828 , marcava as atribuições camarárias e ficaria reconhecida como aquela que teria reduzido o poder das municipalidades diante do incremento político provincial no arranjo imperial. Um dos tópicos que serviriam para referendar este projeto seria seu artigo 24 que propunha que, a partir de então, as câmaras seriam "corporações meramente administrativas", sem exercerem "jurisdição alguma contenciosa" - ou seja, poder de decisão sobre conflitos - conforme elas desempenhavam historicamente desde o período colonial.

A historiografia tem discutido, e avançado na questão de como as províncias passariam a almejar espaços legítimos de poder e decisão, fosse por meio da criação de instrumentos de extração de recursos, de força armada, de políticas intervenção nos territórios e mapeamento de seus agentes, ou de vários outros, e mesmo em meio a tensões que elas provocariam em relação à Corte imperial. ${ }^{25} 0$ que é indiscutivel. No entanto, há indícios de que as mesmas Câmaras não apenas continuariam portadoras de amplos poderes de decisão, como rivalizariam e resistiriam a parte dos mecanismos de extração de poder dentro ou fora das províncias. ${ }^{26}$ Ainda estão por serem feitos mais estudos nesse sentido, que entrassem propriamente nos mecanismos de construção estatal diante da imperiosidade dos poderes domésticos, estes provenientes de uma longa tradição e marcados pela força das esferas privadas de coerção - da qual a reinvenção da escravidão é, sem dúvida, um exemplo. Não para se provar a suposta ineficácia dos dispositivos estatais, dos meios de extração de força, o que seria uma alternativa fácil e reiterada no Brasil para justificar sua ausência, ou mesmo sua debilidade. Há que se conceber que analisar a história do Estado é lidar com a decomposição dos mecanismos legítimos de produção e reprodução de uma certa ideia do social, para além das disputas políticas, bem como com o equacionamento dos elementos discursivos na concepção de uma ordem pública. ${ }^{27}$

Para tanto, é fundamental termos em mente sua dimensão cultural. Não apenas aquela que o próprio Estado cria e institui, por via de mecanismos mais ou menos violentos, mas como um amplo quadro de padrões, comportamentos, representações e práticas que dão sentido à vida de suas instituições. Dimensão esta que foi negligenciada no passado, fosse por uma historiografia que, mesmo que em alguns casos critica, tendia a entender o Estado como "aparato" ou "artefato" de poder tirânico; fosse por leituras que desvalorizassem a "cultura" em nome precisamente de um racionalismo estatal alicerçado na ideia de progressão de ordenamento que deveria ser almejada por todos, em todos os tempos. ${ }^{28}$ Ambos posicionamentos encontram-se atualmente bastante matizados. Um aspecto em que a abordagem culturalista tem sobejamente permitido encarar aparentes paradoxos para compreensão do Estado é a jurídica, renovada nas últimas décadas sob bases da antropologia cultural, e em reposta a esquemas interpretativos que tendiam a enquadrar o direito como uma mera esfera reprodutora do jogo político. ${ }^{29}$ Neste sentido, o reconhecimento das operações discursivas que Ihe dão sentido como parte de um campo específico de reprodução social tem trazido avanços e novas perguntas acerca da construção jurídica dos Estados.

Nessa linha, tomando novamente o exemplo do Império do Brasil, nos ocorrem alguns questionamentos que envolvem o tema da produção de um arcabouço legal sob o regime constitucional. É fato sabido que, logo após a Independência, declarou-se em vigor toda a legislação pela qual se regia o Brasil - especificamente até abril de 1821, quando D. João voltou à Portugal, 
30

Lei de 20 de outubro de 1823. Coleção das Leis do Império do Brasil de 1823. Rio de Janeiro: Imprensa Nacional, 1887.

31

Vale dizer que o Código Civil, com destaque em relação aos outros, viria a mimetizar, a partir do movimento constitucional originado das experiências revolucionárias baseadas no primado da lei, o ideal de transformação almejado por meio da consolidação de uma ideia abstrata de indivíduo, que deveria ser regido por regras claras e universais. Com isso, opunha-se à uma tradição de "códigos" como mera compilação de leis para instaurar um novo marco legal que passaria a ditar o que seria, a partir dele, o direito válido. 0 que originaria uma série de problemas e impasses que não nos cabe discutir aqui, obviamente. Sobre o tema, CLAVERO, Bartolomé. Código como fuente de derecho y desague de Constitución en Europa. Revista Española de Derecho Constitucional, $n^{\circ}$ 60, p. 11-43, 2000.

32

Uma que nos parece especialmente instigante, está presente em LOPES, José Reinaldo de L.. $A$ formação do direito comercial brasileiro. A criação dos tribunais de comércio do Império. Cadernos Direito GV. São Paulo: Fundação Getúlio Vargas, v. 4, n. 6, novembro/2007.

GARRIGA, Carlos; SLEMIAN, Andréa. Op.cit. bem como aquelas promulgadas por D. Pedro desde então, especificando-se os decretos das Cortes Portuguesas que teriam validade. ${ }^{30}$ Mesmo estando prevista na Constituição de 1824, a criação de novos códigos - os quais passavam a ser concebidos como fontes primordiais de positivação do direito na forma de regras claras que deveriam pautar a definição de suas matérias - teria um caminho errático. Retirando a precocidade do Código Criminal, aprovado em 1830, seguido pelo do Processo Criminal em 1832 (que definia essencialmente procedimentos), e décadas depois pelo Comercial de 1850, 0 Império não veria um Código Civil. ${ }^{31} 0$ que não ocorreria sem um reiterado protesto de muitos juristas, sob a permanente cantilena de um emaranhado confuso de fontes legislativas mimetizadas pela sobrevivência pujante das Ordenações Filipinas e do conjunto difuso de alvarás e decretos que forneciam maior complexidade na determinação do direito de âmbito civil. Várias razões poderiam ser pensadas para a ausência de um Código Civil, e a despeito da existência de projetos para sua criação já desde as últimas décadas do século XIX. ${ }^{32}$ É significativo que, mesmo após a implantação da República em 1889, ainda se tardaria quase duas décadas para que um projeto de Código Civil pudesse ser aprovado. Tendo em vista que ele não apenas definiria o individuo e suas formas de registros, mas todo o universo que deveria regular a vida civil no que tocasse à família, heranças e sucessões, entre outras, sua não aprovação demonstra uma significativa convivência - note-se que não usamos aqui a palavra descompasso - entre o discurso acerca de sua necessidade e a profunda adaptação, e mesmo eficácia, das formas antigas existentes de determinação do direito reconstruídas em uma realidade constitucional (que primava pelo discurso do império da lei em oposição ao pluralismo das fontes de direito identificados a uma ordem tradicional). ${ }^{33}$ Também se pode argumentar que não foram poucos os embates referentes aos mecanismos regulatórios do poder público sobre a vida civil e familiar, cujos interstícios ainda não foram, ao menos nesta chave, suficientemente dissecados por recentes estudos. Mas ninguém, no início do século XX, imaginava que se poderia ficar sem um Código Civil, e a solução da incorporação do antigo/tradicional, da permanente utilização de mecanismos de reforma, bem como a projeção/espera por tempos mais alvissareiros para a construção de um Estado fictício, diz muito acerca da sua cultura jurídica.

\section{Considerações finais}

As pretensões destas páginas são pequenas diante de um problema que nos parece assaz complexo e igualmente necessário de ser discutido como é o do Estado. Ainda mais em sociedades como a nossa, em que ele, na grande maioria das vezes, parece estar realmente ausente, ou, quando presente, criando a permanente sensação de servir muito mais como apareIho de punição do que proteção dos direitos da população. No entanto, sua constante, e até mesmo ultimamente reforçada, evocação como protagonista na mediação de uma série de conflitos deve ser levada em conta, seja para tratar de um fantasma que ainda nos assombra, ou de um cadáver que a olhos visto se deteriora. Impossivel ignorar esse quadro quando se advoga, com todas as tintas e consequências, acerca da importância de indagar-nos sobre sua historicidade e formas de entendê-lo. Reflexão que aqui só foi possivel a partir da feliz escolha do texto de Juan Pro Ruiz para o Fórum desta Revista. Dessa forma, resta-nos dizer que estamos à espreita para a necessidade de continuar pensando o Estado enquanto categoria analítica, enquanto realidade histórica, também no que se refere às suas espe- 
cificidades culturais americanas no contexto de inícios do século XXI; mas igualmente vigilantes para os embates presentes atualmente no campo da administração pública - como no Brasil de 2016-, aonde somos muito mais que meros expectadores isentos.

\section{Bibliografia}

ADAMS, Julia (ed.) (et. alli). Remaking Modernity: Politics, History, and Sociology (Politics, History, and Culture). Durham: Duke University Press Books, 2005

ANNINO, Antonio (coord.). La revolución novohispana, 1808-1821. México: CIDE/FCE/Conaculta/INEHRM/Fundación Cultural de la Ciudad de México, 2010.

BENIGNO, Francesco. Ancora lo 'stato moderno' in alcune recenti sintesi storiografiche. Storica, Roma: Viella, n. 23, p. 119-145, 2002.

. Francesco. Las palabras del tiempo. Un ideario para pensar históricamente. Madrid: Cátedra, 2013.

BERBEL, Márcia; FERREIRA, Paula. Soberanias em questão: apropriações portuguesas sobre um debate iniciado em Cádis. In: BERBEL, M.; OLIVEIRA, Cecília Helena de S. (org.). A experiência constitucional de Cádis - Espanha, Portugal e Brasil. São Paulo: Alameda, 2012, v. 1, p. 169-200.

BOBBIO, Norberto; BOVERO, Michelangelo. Sociedad y Estado en la Filosofía Política Moderna. Mexico : Fondo de Cultura Economica, 1979.

BOURDIEU, Pierre. Sobre o Estado. Cursos no Collège de France (1989-92). São Paulo: Companhia das Letras, 2014.

CARVALHO, José Murilo de. A construção da ordem. A elite política imperial. Brasília: UnB, 1981.

CALDERÓN, María Teresa; THIBAUD, Clément (orgs.). Las revoluciones en el mundo atlántico. Bogotá: Taurus - Universidad Externado de Colombia, 2006.

CHUST, Manuel; SERRANO, José (eds.). Debates sobre las independências iberoamericanas. Frankfurt am Main: Vervuert/lberoamericana/Ahila, 2007.

CLAVERO, Bartolomé. Código como fuente de derecho y desague de Constitución en Europa. Revista Española de Derecho Constitucional, $n^{\circ} 60$, p. $11-43,2000$.

. Bartolomé. Happy Constitution. Cultura y lengua constitucionales. Madrid: Trotta, 1997.

COSTA, Pietro ; ZOLO, Danilo (orgs.). 0 Estado de Direito. História, teoria, crítica. São Paulo: Martins Fontes, 2006.

DOLHNIKOFF, Miriam. 0 Pacto Imperial: Origens do federalismo do Brasil. São Paulo: Globo, 2005.

FRASQUET, Ivana; SLEMIAN, A. (orgs.). De las independencias iberoamericanas 
a los estados nacionales (1810-1850): 200 años de historia. Madrid/ Frankfurt: Iberoamericana/Vervuert, 2009.

GARAVAGLIA, Juan. Servir al Estado, servir al poder: la burocracia en el proceso de construcción estatal en América Latina. Almanack, Guarulhos, n.3, p. 5-26, maio 2012. Disponivel em http://www.almanack.unifesp.br/ index.php/almanack/article/view/907. Acesso em: 01 maio 2016.

GARAVAGLIA, Juan Carlos; PRO RUIZ, Juan (orgs.). Latin American Bureaucracy and the State Building Process (1780-1860). Newcastle: Cambridge Scholars Publishing, 2013, p. 402-427.

GARRIGA, Carlos. La cuestión es saber quién manda ? Historia política, história del derecho y 'punto de vista'. PolHis, n.10, p.89-100, 20. semestre 2012.

. Carlos. Legislación y códigos. In: LORENTE, Marta; VALLEJO, Jesús. Manual de Historia del Derecho. Valencia: Tirant lo Blanch, 2012, p.407-449.

. Carlos; SLEMIAN, Andréa. "Em trajes brasileiros": justiça e constituição na América ibérica (c. 1750-1850). Revista de História (USP), v.169, p.181-221, 2013.

GOUVÊA, Maria de Fátima Silva. 0 império das províncias: Rio de Janeiro, 1822-1889. Rio de Janeiro: Civilização Brasileira, 2008.

GRIMM, Dieter. Constitucionalismo y derechos fundamentales. Madrid: Trotta, 2006.

JANCSÓ, István (org.). Brasil. Formação do Estado e da nação. São Paulo/ljuí: Hucitec/ Fapesp/Unijuí, 2003.

KOSELLECK, Reinhart. Futuro Passado. Contribuição à semântica dos tempos históricos. Rio de Janeiro: Contraponto/Editora Puc-RJ, 2006.

LEMPERIĖRE, Annick. La historiografía del Estado en Hispanoamérica. Algunas Reflexiones. In: PALACIOS, Guillermo (coord.). Ensayos sobre la nueva Historia Política de América Latina, siglo XIX. México: El Colegio del Mexico, 2007, p. 45-62.

. Annick. El Estado en los espacios ibéricos: ¿orden natural o máquina perfomativa? In: FERNANDEZ SEBASTIÁN, Javier (dir.); LEMPERIĖRE, Annick. (ed.). Diccionario político e social del mundo americano. Estado. Madrid: UPV/ Centro de Estudios Políticos e Constitucionales, 2014, p. 15-33. (Iberconceptos II, tomo 3)

LOPES, José Reinaldo de L.. A formação do direito comercial brasileiro. A criação dos tribunais de comércio do Império. Cadernos Direito GV. São Paulo: Fundação Getúlio Vargas, v. 4, n. 6, novembro/2007.

MATTOS, IImar Rohloff de. 0 tempo saquarema. A formação do Estado imperial. Rio de Janeiro, Access Editora, 1999.

PIMENTA, João Paulo. The Independence of Brazil: a review of the recent historiographic production. E-journal of Portuguese History, v.7, n.1, 2009, p.64-85. 
. João Paulo. Brasil y las independencias de Hispanoamérica. Castelló de la Plana: Universitat Jaume I, 2007

RAG0, Margareth. 0 efeito-Foucault na historiografia brasileira. Tempo Social, São Paulo: USP, 7 (12), p. 67-82, 1995.

ROSANVALLON, Pierre. L'Etat en France de 1789 à nous jours. Paris: Éditions du Seuil, 1990.

. Pierre. 0 Liberalismo Econômico: História da ideia de mercado. São Paulo: Edusc, 1999.

SANTOS, Cristiane Alves C. dos Santos. Escrevendo a história do futuro: a leitura do passado no processo de independência do Brasil. Dissertação (Mestrado em História Social). Faculdade de Filosofia, Letras e Ciências Humanas, Universidade de São Paulo, São Paulo, 2010.

SEWELL Jr., William H.. Logics of History: Social Theory and Social Transformation. Chicago: University of Chicago Press, 2005.

SLEMIAN, Andréa. As 'leais corporações'. Revista do Arquivo Publico Mineiro, v. L, p. 24-33, 2014.

. Andréa. Sob o império das leis: constituição e unidade nacional na formação do Brasil (1822-1834). São Paulo: Hucitec, 2009.

STEINMETZ, George (org.). State/Culture. State-formation after the Cultural Turn. Ithaca: Cornell University Press, 1999. 